\title{
How much does it cost to manage paediatric tuberculosis? One-year experience from The Hospital for Sick Children
}

\author{
Cheryl L Main BSc, Ethel Ying MD, Elaine EL Wang MDCM
}

\begin{abstract}
CL Main, E Ying, EEL Wang. How much does it cost to manage paediatric tuberculosis? One-year experience from The Hospital for Sick Children. Can J Infect Dis 1998;9(6):354-359.
\end{abstract}

\begin{abstract}
BACKGROUND: Tuberculosis (TB) is a major infection with nearly eight million cases annually worldwide. Although the majority of these cases are in the developing world, TB is also a problem in Canada.

OBJECTIVE: To determine the cost of diagnosis and management of paediatric TB in Canada.

DESIGN: Cross-sectional study.

SETTING: In-patients and out-patients at The Hospital for Sick Children, Toronto, a tertiary care centre.

PATIENTS: Patients were included if they had clinical or radiological evidence of TB infection with a positive tuberculin skin test or a positive culture result, and were treated from July 1, 1995, to June 30, 1996. Twenty-two patients met the criteria for inclusion in the study.

OUTCOME MEASURES: Patient characteristics, types of disease, types and numbers of investigations, number of inpatient days and out-patient appointments, course of TB treatment, TB-related complications and antimicrobial resistance were obtained from charts. Costs were derived from allocated hospital costs, Ontario Health Insurance Plan billings and costs provided by the Pharmacy Department at The Hospital for Sick Children.

RESULTS: The total cost for one year of management of paediatric TB in a tertiary care centre was $\$ 211,576$. Pulmonary TB affected one-half of the study patients but accounted for one-quarter of the cost. One case of meningitis resulted in almost the same costs as all cases of pulmonary TB. Hospitalization was the largest contributor to overall cost, accounting for three-quarters of the total. The remaining costs in order of their contribution to overall costs were antimicrobial treatment, out-patient appointments, diagnostic imaging and TB cultures.

CONCLUSIONS: From a hospital's perspective, the costs of managing each of the 22 patients was approximately $\$ 10,000$. However, there was great variability between patients, with much greater costs for those who required hospitalization or numerous investigations because TB was not suspected. To the authors' knowledge, this is the first time that such a cost analysis has been performed for a paediatric population. A cost analysis provides a better measure of the burden of illness than is indicated by the absolute number of patients.
\end{abstract}

Key Words: Cost analysis, Paediatric tuberculosis 


\title{
Combien coûte le traitement de la tuberculose pédiatrique? Expérience d'une année au Hospital for Sick Children
}

\begin{abstract}
HISTORIQUE : La tuberculose (TB) est une infection importante puisque l'on dénombre près de 8 millions de cas chaque année à l'échelle mondiale. Bien que la majorité de ces cas se trouvent dans les pays en voie de développement, la TB constitue également un problème au Canada.

OBJECTIF : Déterminer le coût du diagnostic et de la prise en charge de la TB pédiatrique au Canada.

MODÈLE : Étude transversale.

CONTEXTE : Patients hospitalisés ou non, traités au Hospital for Sick Children de Toronto, un centre de soins tertiaires. PATIENTS : Les patients étaient admis à condition de présenter des signes cliniques ou radiologiques d'infection tuberculeuse avec épreuve cutanée à la tuberculine positive ou résultats de cultures positifs; et d'avoir été traités entre le $1^{\text {er }}$ juillet 1995 et le 30 juin 1996. Vingt-deux patients ont répondu aux critères d'inclusion de l'étude.

MESURES PARAMÉTRIQUES : Les caractéristiques des patients, le type de maladie, ainsi que le nombre d'épreuves diagnostiques et le nombre de jours d'hospitalisation et de rendez-vous en clinique externe, et les données sur les traitements contre la TB, les complications liées à la TB et la résistance aux antimicrobiens ont été tirées des dossiers. Les coûts ont été calculés à partir des coûts hospitaliers alloués, des facturations et des coûts pris en charge par le régime d'assurance-santé de l'Ontario fournis par le département de pharmacie du Hospital for Sick Children.

RÉSULTATS : Le coût total pour une année de prise en charge de la TB pédiatrique dans un centre de soins tertiaires s'est élevé à 211 576,00 \$. La TB pulmonaire a affecté la moitié des patients inscrits à l'étude, mais a représenté le quart des coûts. Les dépenses liées à un seul cas de méningite ont totalisé le même montant que tous les cas de TB pulmonaire regroupés. L'hospitalisation a été le principal élément contributif du coût global représentant les trois quart du total. Les coûts restants, en ordre décroissant et par rapport aux coûts globaux, ont été les traitements antimicrobiens, les rendez-vous en clinique externe, les épreuves d'imagerie diagnostique et les cultures de TB.

CONCLUSIONS : D'un point de vue hospitalier, le coût de la prise en charge de chacun des 22 patients a été d'environ 10000 \$. Toutefois, on a noté une grande variabilité d'un patient à l'autre, les coûts s'étant révélés bien supérieurs dans les cas d'hospitalisation ou d'épreuves diagnostiques multiples quand la TB n'était pas soupçonnée. À la connaissance des auteurs, il s'agit de la première analyse des coûts effectuée auprès d'une population pédiatrique. L'analyse des coûts donne une meilleure idée du fardeau de la maladie que le nombre absolu de patients.
\end{abstract}

A baby was brought to the emergency room by her concerned mother. The infant's clinical presentation was compatible with meningitis. On inquiry, it was determined that the baby's mother had been diagnosed with active pulmonary tuberculosis (TB) and was receiving treatment. However, no prophylaxis had been offered to the baby. Lumbar puncture revealed that cerebrospinal fluid was positive for acid-fast bacilli. The baby was admitted to The Hospital for Sick Children, Toronto, Ontario, for 45 days, during which time she required a shunt and numerous diagnostic tests. The baby was released from hospital but required readmission for infection of her shunt.

The above case of tuberculous meningitis emphasizes the most common source of infection to children and the severity of TB in children. However, does it reflect the overall economic burden of disease? TB is a major infectious disease affecting nearly eight million people worldwide (1). Rates in Canada are lower than those in developing countries and have generally stayed stable; for example, in the period from birth to four years, rates per 100,000 individuals were 4.5, 4.0, 7.0 and 4.6 for the years 1980, 1985, 1990 and 1995, respectively (2). Ontario is the province with the highest number of cases, accounting for an increasing proportion of cases since 1980 (2). Forty per cent of cases in 1995 occurred in Ontario. Despite increasing levels of awareness, little work has been done to assess the economic burden of illness imposed by TB in a developed world setting, particularly among children. Such studies are needed because the risk of infection (3) and the spectrum of disease (4) differ greatly between adult and paediatric populations. In the present times of fiscal restraint, studies examining cost may be of benefit in determining where health care dollars are spent.
The Hospital for Sick Children in Toronto is a tertiary care paediatric centre that is a referral centre for TB management in metropolitan Toronto. The majority of TB cases in Ontario are diagnosed in Toronto because the city is a favoured site for immigrant and refugee settlement. Between 1989 and 1996, the incidence of paediatric TB in the greater Toronto area was 195 of a total of 412 Ontario cases (47\%) (personal communication). This study examines the economic burden of illness imposed by TB disease in the paediatric population cared for at The Hospital for Sick Children during the period from July 1 , 1995, to June 30,1996. Costs were measured by examination of actual clinical cases and consisted of the costs of in-patient and out-patient management, laboratory and imaging investigations, and drug treatment. A minimal cost estimate of the diagnosis and management of paediatric TB in Canada was determined because patients continued to be followed by their primary care physicians during the same period and some Toronto paediatric TB cases would not have been referred to the hospital. These data are useful for illustrating the magnitude of the problem of paediatric TB as well as for suggesting approaches to optimize disease management and prevention.

\section{PATIENTS AND METHODS}

Inclusion criteria: A cross-sectional retrospective study of all TB patients seen at The Hospital for Sick Children was conducted during the period from July 1, 1995, to June 30, 1996. Patients were identified from three sources: charts of patients with a discharge diagnosis of 'TB' obtained from Health Records; charts of TB patients identified from the correspondence files of one of the authors (EELW), who is the designated paediatric referral physician for TB cases identified through the public health system; and charts of patients in which the mi- 
TABLE 1

Diagnostic imaging Ontario Health Insurance Plan fees in dollars

\begin{tabular}{lcccc}
\hline & Radiograph & CT scan & MRI & Ultrasound \\
\hline Head & - & 61.60 & 89.00 & - \\
Chest & 30.71 & 71.90 & 104.30 & - \\
Abdomen & 30.44 & 92.40 & 104.30 & 77.90 \\
Pelvis & - & 92.40 & 104.30 & 77.90 \\
Spine & 42.23 & 92.40 & 144.35 & - \\
\hline
\end{tabular}

CT Computed tomographic; MRI Magnetic resonance imaging

crobiology laboratory reported the presence of acid-fast bacilli or isolation of Mycobacterium tuberculosis from culture. However, charts in which nontuberculous mycobacteria were identified subsequent to TB diagnosis were excluded. Only patients with the active disease during the period from July 1, 1995, to June 30, 1996, were included; therefore, patients followed for TB prophylaxis were not considered. Diagnostic criteria used in the study were clinical or radiological evidence of infection with a positive tuberculin skin test or positive culture results (4). In total, 22 patients were eligible for inclusion in the study. Patients diagnosed before the study period but still receiving treatment during the study period were included in the determination of expenses incurred during that period. Similarly, costs incurred after the study period for patients diagnosed during the study period were excluded. Charts were assessed for patient characteristics, types of disease, types and numbers of investigations, number of in-patient physician visits and out-patient appointments, course of TB treatment, TB-related complications and antimicrobial resistance.

Daily hospitalization (\$978/day), physician visit and diagnostic test charges were obtained from The Hospital for Sick Children and the Ontario Health Insurance Plan (OHIP) billing codes. Drug costs were obtained from the Department of Pharmacy at The Hospital for Sick Children. In-patient and outpatient physician charges included the cost of initial consultation (\$105.40) in each venue, and charges for subsequent inpatient visits (\$17.10/day) and for subsequent clinic visits (\$49.85). The hospital charges a supplemental administrative fee of $\$ 89.00$ for each clinic appointment. The physicians' fees would not normally be charged to OHIP because the Department of Pediatrics at the hospital participates in an Alternative Payment Plan with the Ontario Ministry of Health. However, all visits are recorded through a shadow-billing method. The family of one patient who did not have OHIP coverage was billed directly. Radiological test charges were also obtained from OHIP billing codes. The most commonly ordered tests were radiographs, computed tomographic scans, magnetic resonance imaging, or ultrasound of the head, chest, abdomen, pelvis or spine. These charges included both technical and professional fees (summarized in Table 1). The costs of other studies performed less frequently, such as barium swallow, bone scan, echocardiogram, electroencephalogram, bronchoalveolar lavage and diagnostic tissue biopsy, were obtained and included in cost calculations.

Laboratory culture charges were obtained from the Minis-
TABLE 2

Daily costs of commonly used antituberculous agents in dollars

\begin{tabular}{lccc}
\hline Drug & Infant & Child & Adolescent \\
\hline Isoniazid & 1.00 & 3.00 & 0.07 \\
Rifampin & 3.30 & 9.00 & 2.10 \\
Pyrazinamide & 0.63 & 0.63 & 1.26 \\
Ethambutol & 0.28 & 0.64 & 0.90 \\
Vitamin $\mathrm{B}_{6}$ & - & 0.07 & 0.09 \\
\hline
\end{tabular}

Data kindly provided by Nadya Chorostil (Staff Pharmacist, Department of Pharmacy, The Hospital for Sick Children, Toronto, 1996)

try of Health (personal communication) and were $\$ 13.00$ per culture where $M$ tuberculosis was isolated, and $\$ 90.00$ per identification and sensitivity test. These fees include technician fee and culture costs.

Pharmacy cost for antituberculous drugs are listed in Table 2. Drug costs were calculated by factoring in estimates of the average weights for infants $(7.5 \mathrm{~kg})$, for children $(30 \mathrm{~kg})$ and for adolescents $(60 \mathrm{~kg})$. Pharmacy charges of $\$ 11.00$ per twomonth prescription were included. Treatment duration for pulmonary, pleural, abdominal, skin or lymph node TB caused by drug-sensitive organisms was two months with three drugs (isoniazid, rifampicin, pyrazinamide) followed by four months with two drugs (isoniazid, rifampicin), for a total treatment period of six months. For meningitis or osteomyelitis caused by drug-sensitive organisms, treatment duration was two months with three drugs (isoniazid, rifampicin, pyrazinamide) followed by 10 months with two drugs (isoniazid, rifampicin), for a total treatment duration of 12 months. For infection with possible drug-resistant organisms, treatment duration was two months with four drugs (isoniazid, rifampicin, pyrazinamide, ethambutol or other) until susceptibility results were available followed by 10 months of treatment with three drugs (rifampicin, pyrazinamide, ethambutol or other) to which the organisms were sensitive, for a total treatment period of 12 months (5). Drugs chosen in antibiotic resistance cases depended on drug susceptibility results. Families are not charged for antituberculous therapy, but the Public Health Branch of the Ontario Ministry of Health is billed for the therapy.

\section{RESULTS}

Patient characteristics: The patient population consisted of 15 females and seven males, with ages ranging from nine months to 17 years and five months. The average age was $10 \pm 1.25$ years. All but one child had a response of greater than $10 \mathrm{~mm}$ to a five tuberculin unit tuberculin skin test, or had a response of greater than $5 \mathrm{~mm}$ with a known contact or apical scarring. All patients were screened for human immunodeficiency virus infection and tested negative.

Seventeen of the 22 children in the study (77\%) were born outside of Canada. Of these patients, five were born in Somalia; three were born in the Philippines; two were born in Guyana; two were born in Ethiopia; and one child was born in each of China, Hong Kong, Jamaica, Thailand and Vietnam. The children born in Canada had parents from areas in which 
TABLE 3

A breakdown of the costs for management of various tuberculosis syndromes

\begin{tabular}{|c|c|c|c|c|c|c|c|c|}
\hline \multirow[b]{2}{*}{ Syndrome } & \multicolumn{8}{|c|}{ Management of disease costs (\$) } \\
\hline & $\begin{array}{l}\text { Number of } \\
\text { patients }\end{array}$ & Out-patient & Hospital & Diagnostic imaging & $\begin{array}{c}\text { Mycobacterium } \\
\text { tuberculosis culture }\end{array}$ & $\begin{array}{c}\text { Antituberculous } \\
\text { drug }\end{array}$ & Total & Cost/patient \\
\hline Pulmonary & 11 & 6,165 & 26,313 & 838 & 1,030 & 17,409 & 51,755 & 4,705 \\
\hline Bone & 4 & 2,722 & 27,309 & 2,255 & 884 & 4,092 & 37,262 & 9,316 \\
\hline Peritonial & 3 & 3,499 & 58,647 & 2,332 & 1,017 & 1,572 & 67,067 & 22,356 \\
\hline Lymph node & 2 & 2,583 & 1,083 & 143 & 103 & 2,506 & 6,418 & 3,209 \\
\hline
\end{tabular}

TB is endemic. Many also had a history of travel to endemic areas.

Cost of disease: The overall cost for TB diagnosis and treatment in 22 paediatric patients during the period from July 1 , 1995 , to June 30,1996 , was $\$ 211,576$. Costs were calculated in two ways - by disease syndrome and by contributors to cost (Table 3). Thus, pulmonary TB, for example, affected $50 \%$ of the patients but accounted for less than $25 \%$ of the total cost. In contrast, the most expensive case involved an infant with meningitis who required ventricular peritoneal shunt placement and who sustained shunt infections prolonging hospitalization.

Thirteen of 22 patients (59\%) were hospitalized for a total of 157 hospital days, accounting for $77 \%$ of total costs. The other contributors to cost, in order of magnitude, were antituberculous therapy, out-patient visits, diagnostic tests and mycobacterial cultures (Figure 1).

\section{DISCUSSION}

The cost burden of diagnosing and treating 22 paediatric patients with TB disease at The Hospital for Sick Children during the period from July 1,1995 , to June 30 , 1996, was $\$ 211,576$. To our knowledge, this is first Canadian cost assessment for TB in the paediatric population. The average cost of $\$ 9,617$ to manage one child with TB compares with an average cost of $\$ 1,512$ per hospital stay for bronchiolitis, one of the commonest reasons for hospitalization with a paediatric lower respiratory tract infection.

The largest contributor to the overall cost burden was hospitalization. Hospital stays accounted for $77 \%$ of the total cost, which is similar to the percentage found in adult TB studies in the United States (7). The frequency of hospitalization may be surprising in light of the fact that TB is mainly considered an ambulatory disease (8). The high frequency of hospitalization, however, stresses the severe nature of TB in children. The diseases most frequently requiring hospitalization were disseminated diseases, which occur most commonly in infants and children (9).

The finding that pulmonary disease was the most common form of TB disease was anticipated because this form of TB accounts for $85 \%$ of TB cases on average $(10,11)$. It was somewhat surprising that pulmonary disease accounted for $50 \%$ of patient diagnoses but less than $25 \%$ of the total cost burden.

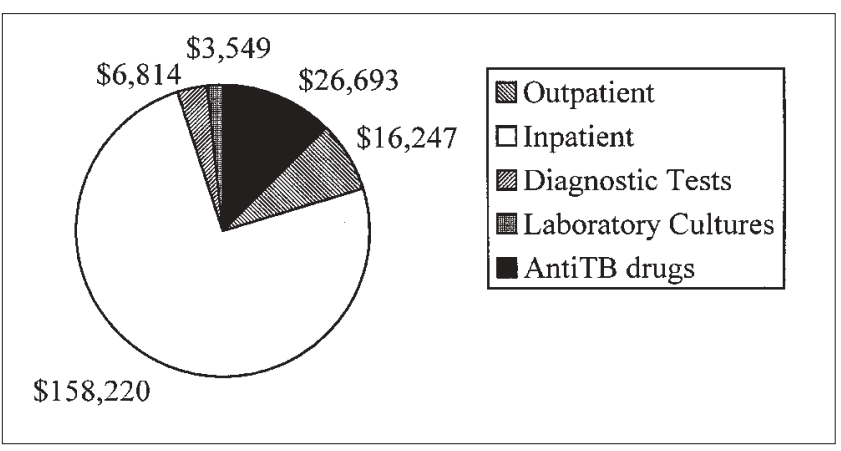

Figure 1) Total costs of paediatric tuberculosis cases by contributor to costs. TB Tuberculosis

One reason for this discrepancy is that pulmonary TB may be recognized earlier than other forms of the disease due to greater diagnostic suspicion (12) or the greater number of symptoms early in the disease (13), thereby avoiding hospitalization. There is often difficulty in diagnosing extrapulmonary TB $(12,14)$ and, thus, it has a greater cost associated with tests, biopsies and treatment.

This cost study is not without limitations. One of the major difficulties encountered was the variability of cost assessed per patient. However, we feel that this accurately reflects the heterogeneous spectrum of disease caused by TB. Several important factors were not considered in determining the cost imposed by TB. Costs to the study children and their families were not considered, with either respect to their pain and suffering or indirect costs such as lost wages and expenses, for travel to the hospital, for example. In addition, it was extremely difficult to capture all of the costs involved with the initial diagnosis of TB. These included costs for diagnostic testing and laboratory cultures performed during the process of ruling out alternative diagnoses and treatment initiated for these diagnoses. Other medications not directly related to the treatment of TB were also not considered. Therefore, we have underestimated the cost of managing TB. The small sample assessed in the study also limited the ability to assess the impact of drug resistance on the cost burden imposed by TB. Unfortunately, the application of this data to the rest of Canada is somewhat limited by the use of OHIP billing codes; however, the data provide us with some idea of the magnitude of TB as a problem in the paediatric population. The costs of directly observed 
therapy were not factored into this analysis because this form of administration was not available for the majority of patients managed in 1995. However, because this is considered optimal therapy (15) and is becoming more available, it would be worthwhile to include these costs in future assessments.

Many consider TB to be a problem only in developing countries. This study emphasizes the lack of boundaries of this disease. Nearly one-quarter of a million dollars is expended each year for the diagnosis and management of paediatric TB in Canada's largest city. A separate analysis has shown that the cost of screening followed by prophylaxis in a subgroup of TB skin test-positive high risk students in Toronto to be $\$ 13,493$ per case of TB prevented (16). Yuan et al (16) demonstrated that the obstacles of providing prophylaxis include poor physician and patient compliance to a screening-based strategy for TB control. Given the average cost of management of paediatric TB estimated in the present study to be $\$ 10,000$,

\section{REFERENCES}

1. Raviglione MC, Snider DE Jr, Kochi A. Global epidemiology of tuberculosis: morbidity and mortality of a worldwide epidemic. JAMA 1995;273:220-6.

2. Njoo H, Nault P. Tuberculosis in Canada, 1995. Ottawa: Health Canada, 1997.

3. Starke JR, Jacobs RF, Jereb J. Resurgence of tuberculosis in children. J Pediatr 1992;120:839-55.

4. Starke JR, Correa AG. Management of mycobacterial infection and disease in children. Pediatr Infect Dis J 1995;14:455-70.

5. Committee on Infectious Diseases, American Academy of Pediatrics. Tuberculosis. In: Peter G, Halsey NA, Marcuse EK, Pickering LK, eds. 1994 Red Book: Report of the Committee on Infectious Diseases. Elk Grove Village: American Academy of Pediatrics, 1994:480-500.

6. Langley JM, Wang EEL, Law BJ, et al. Economic evaluation of respiratory syncytial virus infection in Canadian children: a Pediatric Investigators Collaborative Network on Infections in Canada (PICNIC) study. J Pediatr 1997;131:113-7.

7. Brown RE, Miller B, Taylor WR, et al. Health-care expenditures for tuberculosis in the United States. Arch Intern Med 1995;155:1595-600. a school screening-based prophylaxis program would not appear to be cost effective. The inefficiency of a school screening-based prophylaxis program does not negate the cost effectiveness of screening and providing prophylaxis for family contacts of a person with TB $(3,4)$. Such an inexpensive intervention would have prevented the hospitalization of the baby with tuberculous meningitis mentioned above, the attendant costs of her hospitalization and, as important, at least her sequelae.

ACKNOWLEDGEMENTS: We acknowledge Albert Hadad, chief technologist of the TB Laboratory, Ontario Ministry of Health, Toronto, Ontario, and Nadya Chorostil, staff pharmacist at the Department of Pharmacy, The Hospital for Sick Children, Toronto, Ontario, for kindly providing us with cost data; and Diane Kerbel, an epidemiologist nurse at the Ontario Ministry of Health, Toronto, Ontario, for kindly providing us with tuberculosis incidence rates.

8. Tuberculosis Committee, Canadian Thoracic Society. Essentials of tuberculosis control for the practicing physician. Can Med Assoc J 1994;150:1561-71.

9. Doerr CA, Starke JR, Ong LT. Clinical and public health aspects of tuberculous meningitis in children. J Pediatr 1995;127:27-33.

10. Remington JS, Hollingworth GR. New tuberculosis epidemic: Controversies in screening and preventive therapy. Can Fam Physician 1995;41:1014-23.

11. Fitzgerald JM. Tuberculosis in the 1990s: Issues for primary care physicians. Can Fam Physician 1995;41:1030-6.

12. Enarson DA, Ashley MJ, Grzybowski S, Ostapkowicz E, Dorken E. Non-respiratory tuberculosis in Canada. Epidemiologic and bacteriologic features. Am J Epidemiol 1980;112:341-51.

13. Vallejo J, Ong LT, Starke JR. Clinical features, diagnosis, and treatment of tuberculosis in infants. Pediatrics 1994;94:941-7.

14. Awareness of tuberculosis. Br Med J 1973;1:308. (Edit)

15. WHO report on the tuberculosis epidemic of 1997. Geneva: World Health Organization, 1997.

16. Yuan L, Richardson E, Kendall PR. Evaluation of a tuberculosis screening program for high-risk students in Toronto schools. Can Med Assoc J 1995;153:925-32. 


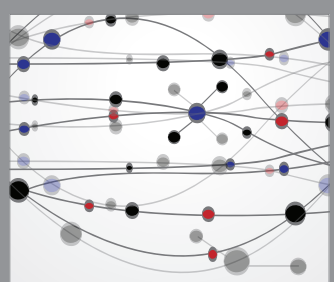

The Scientific World Journal
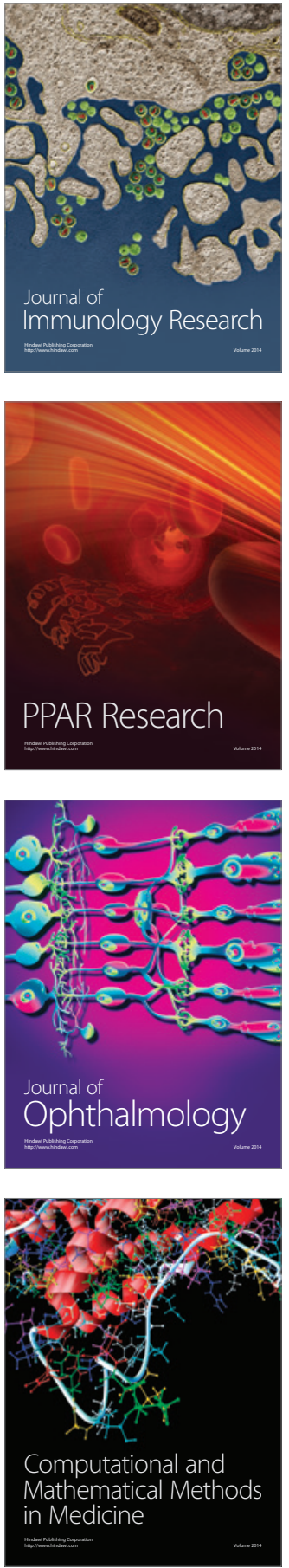

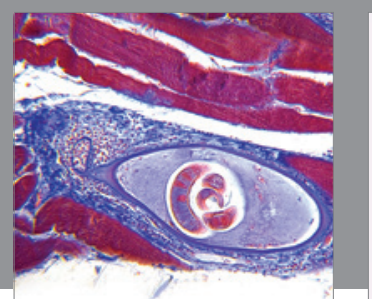

Gastroenterology Research and Practice

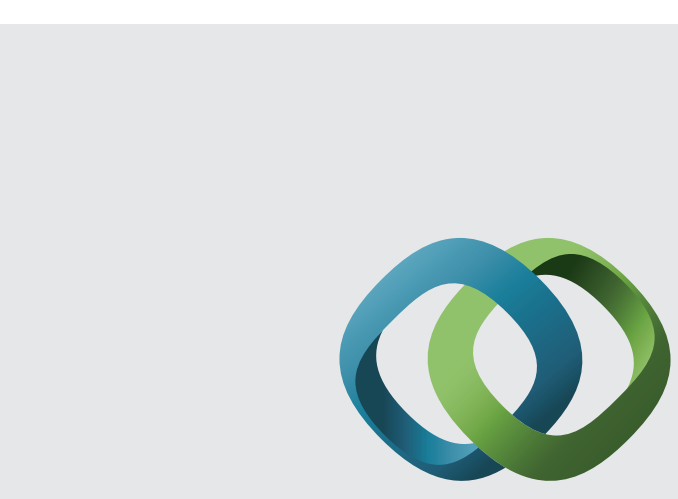

\section{Hindawi}

Submit your manuscripts at

http://www.hindawi.com
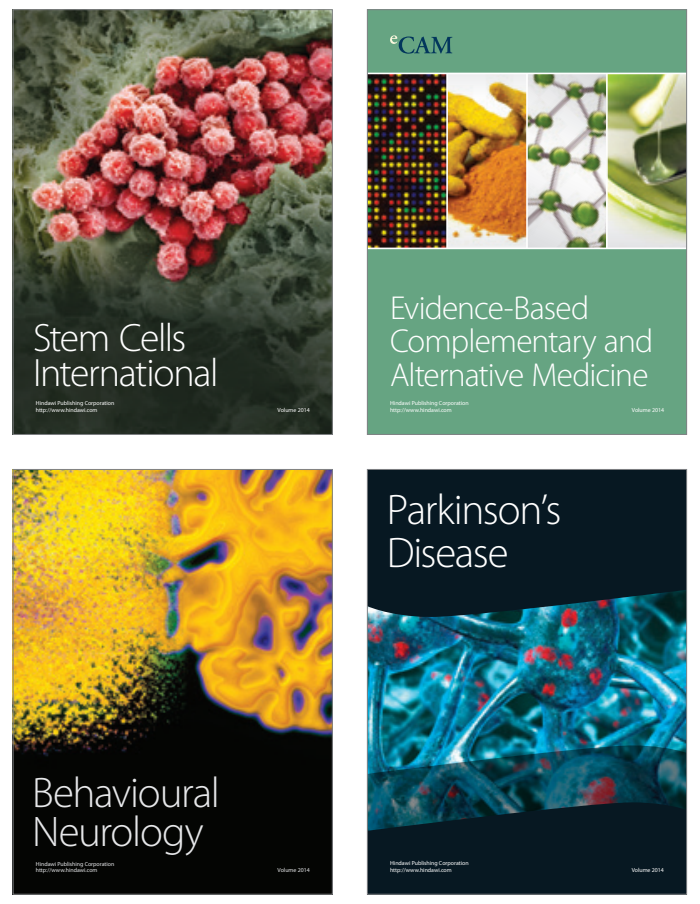
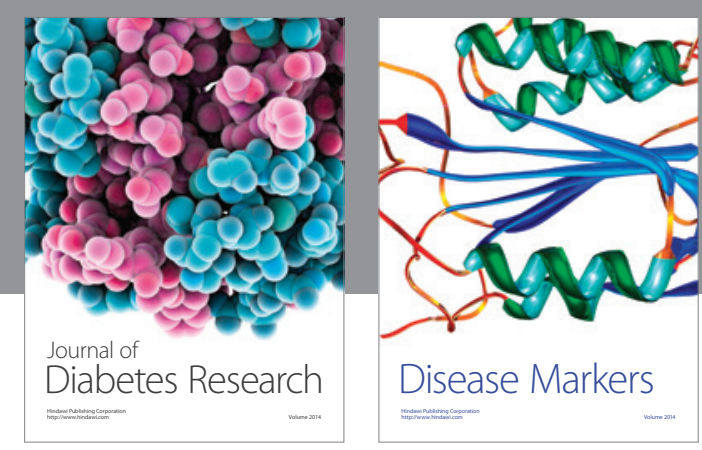

Disease Markers
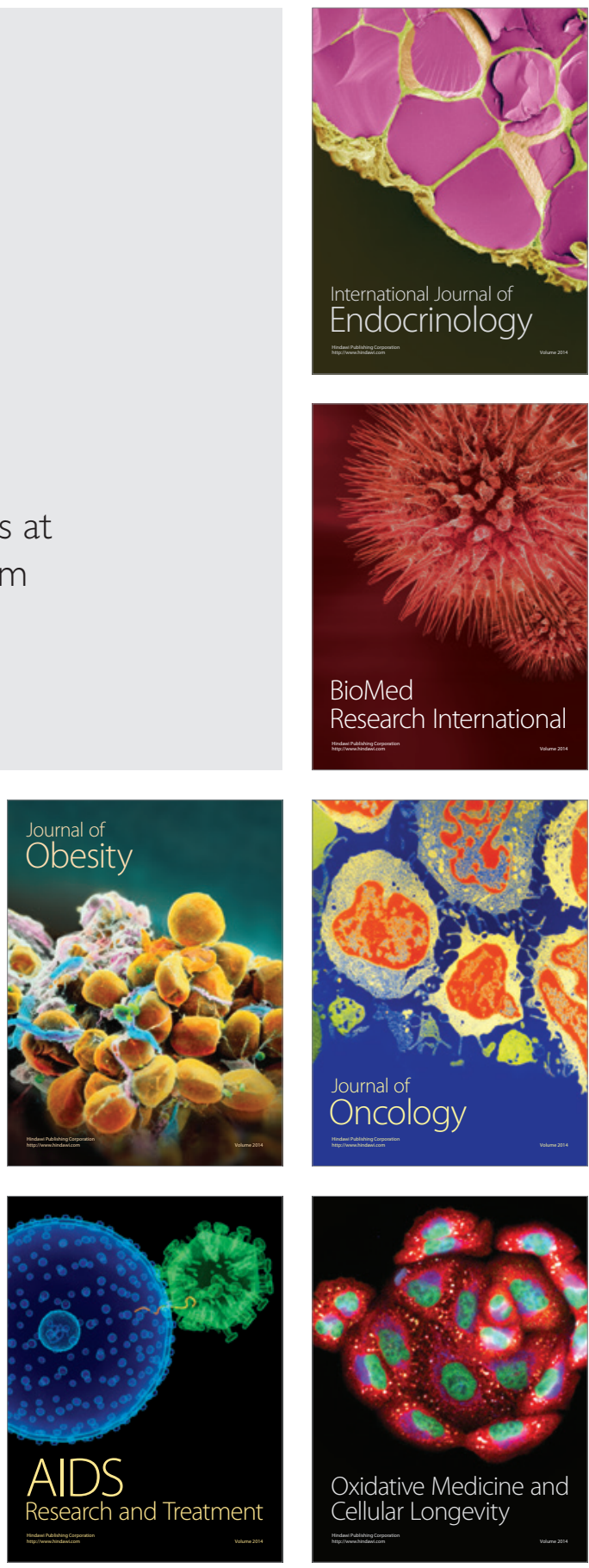